\title{
Article
}

\section{RNF8-CDH1 Co-Expression Predicts Clinical Benefit of Chemoradiotherapy in Triple-Negative Breast Cancer}

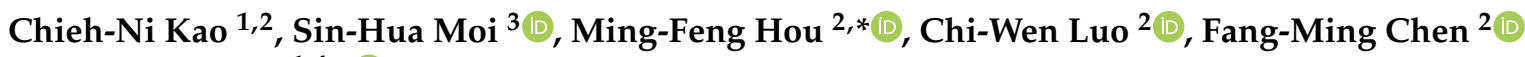 \\ and Mei-Ren Pan 1,4,*(D) \\ 1 Graduate Institute of Clinical Medicine, Kaohsiung Medical University, Kaohsiung 807, Taiwan; \\ jennykao0320@gmail.com \\ 2 Division of Breast Oncology and Surgery, Department of Surgery, Kaohsiung Medical University Hospital, \\ Kaohsiung 807, Taiwan; cwlo0623@gmail.com (C.-W.L.); fmc5464@gmail.com (F.-M.C.) \\ 3 Center of Cancer Program Development, E-Da Cancer Hospital, I-Shou University, Kaohsiung 824, Taiwan; \\ moi9009@gmail.com \\ 4 Drug Development and Value Creation Research Center, Kaohsiung Medical University, \\ Kaohsiung 807, Taiwan \\ * Correspondence: mifeho@kmu.edu.tw (M.-F.H.); mrpan@cc.kmu.edu.tw (M.-R.P.); \\ Tel.: +886-7-3121101-6060 (M.-F.H.); +886-7-3121101-5092-94 (M.-R.P.); Fax: +886-7-3218309 (M.-R.P.)
}

check for updates

Citation: Kao, C.-N.; Moi, S.-H.; Hou, M.-F.; Luo, C.-W.; Chen, F.-M.; Pan, M.-R. RNF8-CDH1 Co-Expression Predicts Clinical Benefit of Chemoradiotherapy in TripleNegative Breast Cancer. J. Pers. Med. 2021, 11, 655. https://doi.org/ 10.3390/jpm11070655

Academic Editor: Kurt D. Christensen

Received: 19 June 2021

Accepted: 8 July 2021

Published: 13 July 2021

Corrected: 15 March 2022

Publisher's Note: MDPI stays neutral with regard to jurisdictional claims in published maps and institutional affiliations.

Copyright: (c) 2021 by the authors. Licensee MDPI, Basel, Switzerland. This article is an open access article distributed under the terms and conditions of the Creative Commons Attribution (CC BY) license (https:/ / creativecommons.org/licenses/by/ $4.0 /)$.
Abstract: Triple-negative breast cancer (TNBC) is the most aggressive breast cancer subtype and exhibits an overall poor outcome. Due to the lack of targeted therapy, conventional systemic chemotherapy has been the main strategy for the treatment of TNBC. Further evidence has shown that combining radiation with chemotherapy is also a suitable treatment based on DNA repair deficiencies in patients with TNBC. However, the preferred treatment for metastatic TNBC remains unclear. Therefore, identification of biomarkers is an unmet need in personalized therapy for TNBC. RNF8 (ring finger protein 8) is a ubiquitin ligase implicated in TNBC metastasis; however, its role in TNBC pathogenesis is unclear. The purpose of the present study was to investigate the roles of the RNF8-CDH1(Cadherin 1) axis in node-positive TNBC patients. We found that the $R N F 8^{h i g h} / C D H 1^{\text {low }}$ index was significantly higher in patients with TNBC than in patients without TNBC. Furthermore, patients with an RNF8high $/ C D H 1^{\text {low }}$ index displayed poorer outcomes than those with an $R N F 8^{\text {low-medium }} / C D H 1^{\text {medium-high }}$ index. Notably, as compared to patients with an

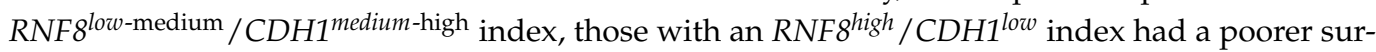
vival rate with chemotherapy treatment alone. The combination of radiation and chemotherapy resulted in a better survival rate than chemotherapy alone in patients with an $R N F 8^{\text {high }} / C D H 1^{\text {low }}$ index. Taken together, the RNF $8^{\text {high }} / C D H 1^{\text {low }}$ index not only functions as a prognostic and therapeutic marker but may also act as a target in the development of anti-cancer agents for patients with TNBC.

Keywords: RNF8; CDH1; TNBC; chemoradiotherapy

\section{Introduction}

Triple-negative breast cancer (TNBC) is a breast cancer subtype that lacks an estrogen receptor (ER), a progesterone receptor (PR), and a human epidermal growth factor receptor 2 (HER2). TNBCs account for $10-20 \%$ of breast cancer cases and are associated with a high level of metastases, high recurrence rates, and the worst prognoses [1]. Approximately $90 \%$ of cancer-related deaths are caused by metastatic diseases [2]. Sometimes, patients with TNBC do not have a second chance to fight the disease owing to its aggressive progression. According to the National Comprehensive Cancer Network (NCCN) v5.2021 guidelines and ESO-ESMO guidelines 2018, chemotherapy is still a standard option for the treatment of metastatic TNBC (mTNBC) [3,4]. Recently, evidence further indicated that a combination of atezolizumab and nab-paclitaxel might be used in patients with programmed death-ligand 1 (PD-L1)-positive advanced TNBC patients for prolonged 
progression-free survival [5]. However, the preferred treatment for metastatic TNBC with visceral crisis remains controversial and requires further study. Thus, obtaining the most accurate treatment is critical. Therefore, it is important to understand the mechanisms of metastasis to improve the therapeutic outcomes of TNBC.

Epithelial-mesenchymal transition (EMT) is a crucial step in the process of invasion and metastasis in solid tumors [6]. EMT can be induced or regulated by signaling pathways controlled by various growth factors and cytokines, including TGF- $\beta$, VEGF, IL6, and EGF, as well as the tyrosine kinase receptor pathway [7-10]. Activation of these pathways leads to transcriptional repression of a series of cell adhesion molecules, including E-cadherin, also known as CDH1(cadherin 1), to further drive cellular mobility [11]. Studies on TNBC cells and tissues have shown that they commonly exhibited an activated EMT program and possessed an enriched cancer stem cell (CSC) population [12,13]. Metastatic and stem-ness-like tumors are generally refractory to primary tumors, with poor response rates and shortened overall survival. Therefore, exploring the molecular basis underlying the status of CSCs and EMT in TNBC may stratify the prognostic and possible therapeutic classifications.

A prior analysis of patient samples further identified that the CSCs accounting for TNBC metastasis harbored an EMT gene signature including TWIST upregulation $[14,15]$. Expression of TWIST is repressed in normal adult tissues but upregulated in TNBC and high-grade breast cancer. TWIST is a well-known transcriptional factor that regulates various physiological processes, including EMT, tumor growth, and chemoresistance [15-17]. A well-known example is that TWIST is a transcriptional repressor of CDH1 gene expression in contributing a malignant phenotype of breast cancer [18]. It has been reported that TGF $\beta$, hypoxia, STAT3, and RNF8 (ring finger protein 8) triggered the expression of TWIST underlying transcriptional and post-translational regulation [19-22]. Therefore, verifying the roles of TWIST-mediated downstream genes and targeting upstream regulators of TWIST may provide a potential strategy for the development of prognostic and therapeutic tools for TNBC.

RNF8, an E3 ubiquitin ligase, is a well-known critical DNA damage-responsive protein involved in the process of DNA repair [23-25]. Recently, several lines further demonstrated that RNF8 played a role in inducing EMT and metastasis in TNBC [22]. Notably, RNF8 promotes EMT via K63-linked ubiquitination and subsequent activation and stabilization of the TWIST protein to further control TWIST-mediated downstream gene expression. This study aimed to further clarify the roles of RNF8 in clinical patient outcomes. To this end, we conducted a serial comprehensive analysis including RNA sequencing (RNA-seq) data from The Cancer Genome Atlas Breast Invasive Carcinoma (TCGA-BRCA) to address the role of RNF8- and TWIST-mediated downstream genes in patients with lymph node (LN) invasion using the Genomic Data Commons (GDC) data portal. In addition to investigating RNF8's role in clinicopathological features and the patient survival rate, we aimed to evaluate its value in therapeutic strategies for patients with TNBC.

\section{Materials and Methods}

\subsection{Data Source}

All data were downloaded from cBioPortal (https:/ /www.cbioportal.org/, accessed date 10 January 2021). The baseline, tumor, and treatment characteristics, and RNA-seq expression in the study population were extracted from the Breast Invasive Carcinoma of the Cancer Genome Atlas Program PanCancer database (TCGA-BRCA). The baseline characteristics included age, race, ethnicity, and breast cancer subtypes. The tumor characteristics included tumor staging (AJCC), lymph node staging (AJCC), and pathological stage. The treatment characteristics included surgery, radiation therapy, chemotherapy, hormone therapy, and target therapy. The study population was divided into the LN subgroup according to LN staging. Patients with LN staging of NX and N0 were defined as the LN-negative ( $\mathrm{LN}-$ ) subgroup, and patients with LN staging of N1 to N3 were defined as the LN-positive (LN+) subgroup. Disease-free survival (DFS) was considered as the 
primary endpoint. Patients who had progression or recurrence events during the follow-up interval were considered as progressive disease; otherwise, they were considered diseasefree. Overall survival (OS) was considered as a secondary endpoint and was defined by the all-cause mortality status of the study population.

\subsection{RNA-seq Expression}

The gene expression profile was experimentally determined using the Illumina HiSeq 2000 RNA Sequencing platform at the University of North Carolina TCGA genome characterization center. RNA-seq expression was computed using the mean normalized (per gene) gene expression by RNA-seq across all TCGA cohorts. In this study, RNA-seq expression of RNF8 and related genes was reported in reads per kilobase million (RPKM) and shown in the log2 (norm_count + 1)-transformed RNA-Seq by expectation-maximization (RSEM) pan-cancer normalized count.

\subsection{UALCAN Data Analysis}

UALCAN (http:/ / ualcan.path.uab.edu, accessed date 19 June 2021) is a web resource that explores cancer transcriptome data, including RNA-seq, promoter methylation, correlation, and survival, using TCGA data. RNF8 expression under different subtypes was analyzed in patients with breast cancer using UALCAN. A $p$-value of less than 0.05 $(p<0.05)$ was considered statistically significant for all results.

\subsection{Statistical Analyses}

The baseline characteristics of the study population were summarized as frequency and percentages or median and range, and the difference in distribution between the LN subgroups was estimated using an independent two-sample $t$-test, a chi-square test, or Fisher's exact test. The correlation of RNA-seq expression between RNF8 and related genes was estimated using Pearson's correlation analysis. The correlation matrix of RNF8 and related genes was illustrated using a heatmap. RNF8 significantly correlated genes were considered candidate genes (GENE). RNA-seq expression of RNF8 and GENE in the LN and TNBC subgroups was visualized using boxplots, and the difference in RNA-seq expression was tested by the Wilcoxon rank-sum test. Optimal cut-off values for RNA-seq expression of RNF8 and each GENE were determined using the X-tile algorithm according to DFS [26]. RNF8 and all GENE were divided into high-, medium-, and low-RNA-seq expression strata according to the corresponding optimal cut-off points. The distribution of the study population according to the RNF8 strata and RNA-seq expression strata of each GENE was illustrated using faceted bar charts in order to identify the differences in TNBC and non-TNBC proportions in each RNF $8 \times$ GENE stratum. The survival curve of RNA-seq expression strata in RNF8, GENE, and RNF8 $\times$ GENE was estimated using the Kaplan-Meier estimator, and the survival difference between strata was tested using the log-rank test. All $p$-values were two-sided, and statistical significance was set at $p<0.05$. All statistical analyses were performed using the computing environment R 4.0.3 (R Core Team, 2020).

\section{Results}

\subsection{Clinicopathological Characteristics and Progression of Breast Cancer}

The clinicopathological characteristics of 498 patients with breast cancer were collected and summarized from TCGA-BRCA of the GDC data portal. The presence of LN metastasis is essential for the formulation of treatment strategies for breast cancer. To build a nomogram that predicts LN metastasis in patients with breast cancer, the obtained breast cancer samples were further divided into LN-negative $(\mathrm{LN}-, n=234)$ and LN-positive $(\mathrm{LN}+, n=264)$ groups. A total of $234 \mathrm{LN}-$ patients, with a median age of 57 years, and $264 \mathrm{LN}+$ patients, with a median age of 56 years, were analyzed. Overall, several clinicopathological factors, including subtypes $(p=0.002)$, T staging $(p<0.001)$, N staging $(p<0.001)$, pathological stage $(p<0.001)$, and treatment choices including radiation therapy 
and chemotherapy $(p<0.001)$, were significantly different between $\mathrm{LN}-$ and $\mathrm{LN}+$ patients (Table 1).

Table 1. Baseline characteristics of study population $(n=498)$.

\begin{tabular}{|c|c|c|c|c|}
\hline Variables & All & LN (-) & LN (+) & $p$ \\
\hline Cases, row \% & 498 & $234(47.0 \%)$ & $264(53.0 \%)$ & \\
\hline Age (years), median (range) & $56(26-90)$ & $57(29-89)$ & $56(26-90)$ & 0.233 \\
\hline Subtype & & & & 0.002 \\
\hline Basal (TNBC) & $114(22.9 \%)$ & $68(29.1 \%)$ & $46(17.4 \%)$ & \\
\hline Her2 & $42(8.4 \%)$ & $19(8.1 \%)$ & $23(8.7 \%)$ & \\
\hline LumA & $220(44.2 \%)$ & $105(44.9 \%)$ & $115(43.6 \%)$ & \\
\hline LumB & $122(24.5 \%)$ & $42(17.9 \%)$ & $80(30.3 \%)$ & \\
\hline $\mathrm{T}$ staging (AJCC) & & & & $<0.001$ \\
\hline $\mathrm{T} 1$ & $152(30.5 \%)$ & $90(38.5 \%)$ & $62(23.5 \%)$ & \\
\hline $\mathrm{T} 2$ & $305(61.2 \%)$ & $135(57.7 \%)$ & $170(64.4 \%)$ & \\
\hline $\mathrm{T} 3$ & $33(6.6 \%)$ & $8(3.4 \%)$ & $25(9.5 \%)$ & \\
\hline $\mathrm{T} 4$ & $8(1.6 \%)$ & $1(0.4 \%)$ & $7(2.7 \%)$ & \\
\hline $\mathrm{N}$ staging (AJCC) & & & & $<0.001$ \\
\hline NO & $234(47.0 \%)$ & $234(100 \%)$ & $0(0 \%)$ & \\
\hline N1 & $181(36.3 \%)$ & $0(0 \%)$ & $181(68.6 \%)$ & \\
\hline N2 & $58(11.6 \%)$ & $0(0 \%)$ & $58(22.0 \%)$ & \\
\hline $\mathrm{N} 3$ & $25(5.0 \%)$ & $0(0 \%)$ & $25(9.5 \%)$ & \\
\hline Pathological Stage & & & & $<0.001$ \\
\hline Stage I & $94(18.9 \%)$ & $90(38 \%)$ & $4(1.5 \%)$ & \\
\hline Stage II & $304(61.0 \%)$ & $143(61 \%)$ & $161(61 \%)$ & \\
\hline Stage III & $100(20.1 \%)$ & $1(0.4 \%)$ & $99(38 \%)$ & \\
\hline Radiation & $321(64.5 \%)$ & $129(55 \%)$ & $192(73 \%)$ & $<0.001$ \\
\hline Chemotherapy & $390(78.3 \%)$ & $167(71 \%)$ & $223(84 \%)$ & $<0.001$ \\
\hline Hormone therapy & $306(61.4 \%)$ & $136(58.1 \%)$ & $170(64.4 \%)$ & 0.179 \\
\hline Target therapy & $306(61.4 \%)$ & $136(58.1 \%)$ & $170(64.4 \%)$ & 0.179 \\
\hline
\end{tabular}

$p$-Value was estimated using independent two-sample $t$-test, chi-square test, or Fisher's exact test.

\subsection{A Significant Correlation among RNF8, SNAI1, and CDH1 mRNA Expression in Patients} with Breast Cancer

It is well known that RNF8 is a RING finger E3 ligase involved in DNA damage repair. A prior study demonstrated that RNF8 facilitated chemoresistance and EMT through ubiquitination of TWIST [22]. TWIST is a basic helix-loop-helix transcription factor required for the activation of oncogenic and mesenchymal genes, including AKT2, TGFB2, PDGFRA, CDH1, SNAI1, CLDN1, RKIP, NPHS2, and CDH2 [27-32]. To further verify the correlation of RNF8-TWIST-mediated downstream genes in breast cancer, Pearson's correlation analysis first confirmed that positive correlations existed between RNF8 and upregulated EMT markers. SNAI1 showed a significant positive correlation $(r$ value $=0.185)$. $C D H 1$ was negatively correlated with RNF8 $(r$ value $=-0.162)($ Table 2$)$.

Table 2. Correlation between RNF8 and involved genes.

\begin{tabular}{ccc}
\hline Genes & $\boldsymbol{r}^{\mathbf{a}}$ & $\boldsymbol{p}$ \\
\hline CDKN1A & 0.001 & 0.991 \\
AKT2 & 0.047 & 0.292 \\
TGFB2 & 0.037 & 0.404 \\
PDGFRA & -0.076 & 0.092 \\
CDH1 & -0.162 & $<0.001$ \\
SNAI1 & 0.185 & $<0.001$ \\
PEBP1 & 0.010 & 0.818 \\
NPHS1 & 0.065 & 0.145 \\
CDH2 & 0.032 & 0.471 \\
\hline
\end{tabular}

\footnotetext{
a Correlation coefficient. $p$-Value was estimated using Pearson's correlation test.
} 


\subsection{High Levels of RNF8 Are Present in Patients with TNBC}

Breast cancer is a heterogeneous disease that is represented by different molecular subtypes and displays various patterns of gene expression, clinical features, responses to treatment, and prognosis. To investigate the contribution of RNF8 to cancer progression in different breast cancer subtypes, we determined RNF8, SNAI1, and CDH1 expression levels in TNBC and non-TNBC breast cancer subtypes using the TCGA RNA-seq dataset. As it is shown in Figure 1, an increase in RNF8 and SNAI1 mRNA levels and a decrease in CDH1 mRNA were observed in $\mathrm{LN}+$ and $\mathrm{LN}-\mathrm{TNBC}$ patients. In contrast to RNF8, SNAI1, and CDH1 mRNA, other TWIST-related downstream genes, including AKT2, TGFB2, PDGFRA, RKIP, NPHS2, and CDH2, were not altered between patients with and without TNBC. These data indicate that RNF8, SNAI1, and CDH1 might play a role in TNBC. Therefore, we focused on studying the correlation between RNF8, SNAI1, and CDH1 in patients with TNBC. To further verify the roles of RNF8 in TNBC, we analyzed its expression in different TNBC subgroups using the UALCAN database. Consistent with the findings shown in Figure 1, high levels of RNF8, SNAI1, and CDH1 were observed in TNBC compared with other subtypes of breast cancer (Figure 2A). According to gene expression profiling and treatment response, TNBC is classified into six distinct subgroups: basal-like 1 (BL1), basallike 2 (BL2), mesenchymal (M), mesenchymal stem-like (MSL), immunomodulatory (IM), and luminal androgen receptor (LAR) [33]. Notably, RNF8 was significantly expressed in the BL1 and M subgroups of TNBC; SNAI1 was significantly expressed in the BL2, IM, MSL, M, and UNS subgroups of TNBC, compared to the luminal and HER2+ subtypes; and $C D H 1$ was significantly downregulated in the BL2, MSL, M, and UNS subgroups of TNBC, compared to BL1 (Figure 2B). Notably, evidence indicates that the BL1 subtype is characterized by the enrichment of cellular proliferation and the DNA damage response. The $\mathrm{M}$ subtype is specifically enriched in the components of differentiation, migration, and tumor growth. This evidence demonstrates that targeting RNF8 might provide therapeutic strategies for the blockade of metastasis and DNA repair ability.

\subsection{Patients with TNBC Display RNF $8^{\text {high }} / C D H 1^{\text {low }}$ Expression}

Next, we used X-tile analysis to establish the cut-off values of RNF8, SNAI1, and CDH1 expression in the TCGA database and survival analyses (Figure $3 \mathrm{~A}-\mathrm{C}$ ). The $\mathrm{X}$-tile analysis with the optimal cut-off value of RNF8 was categorized as low $(-0.2--0.3)$, intermediate $(-0.3-0.6)$, and high (0.6-2.3). CDH1 was categorized as low (-4.9-1.6), intermediate (1.6-2.4), and high (2.4-4.7). SNAI1 was categorized as low (-2.7-0), intermediate (0-1.5), and high (1.5-3.8) based on DFS information. The analyses showed that $R N F 8^{\text {high }} / C D H 1^{\text {low }}$ and $R N F 8^{h i g h} / S N A I 1^{\text {high }}$ expression was positively associated in patients with TNBC subtypes, compared to non-TNBC subtypes (Figure $3 \mathrm{D}, \mathrm{E}$ ). These data suggest that the patterns of $R N F 8^{\text {high }} / C D H 1^{\text {low }}$ and RNF ${ }^{\text {high }} /$ SNAI1 high might function as diagnostic markers for distinguishing between TNBC and non-TNBC cells.

\subsection{RNF8 $8^{\text {high }} / C D H 1^{\text {low }}$ Functions as a Poor Prognostic Marker for LN+ TNBC Patients}

LN positivity is positively correlated with a higher recurrence rate of TNBC and poorer clinical outcomes. To verify the clinical role of the levels of RNF8, SNAI1, and CDH1 in outcomes in LN+ TNBC patients, we used Kaplan-Meier survival curves to evaluate the predictive value of their expression levels on DFS. As it is shown in Figure 4A-C, there was a trend toward poorer DFS in LN+ patients with $R N F 8^{\text {medium }} /$ high and SNAI1 ${ }^{\text {medium }} /$ high $^{\text {higa }}$. tients with $C D H 1^{\text {low }}$ /medium had a minor trend toward poorer DFS, compared to $C D H 1^{\text {high }}$. This evidence indicates the levels of RNF8 $8^{\text {medium }} /$ high and SNAI1 ${ }^{\text {medium }} /$ high as high-risk strata in LN+ patients, compared to RNF8 $8^{\text {low }}$ and SNAI1 low. Then, LN+ TNBC patients were clustered into two subgroups according to the expression status derived from two gene clusters. Figure $4 \mathrm{D}$ compares the survival curves between $R N F 8^{\text {high }} / C D H 1^{\text {low }}$ and

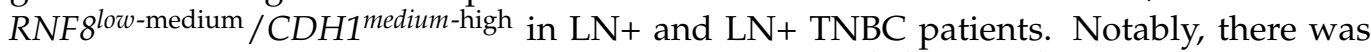
a trend toward poorer DFS in $\mathrm{LN}+$ patients with $R N F 8^{\text {high }} / C D H 1^{\text {low }}$ expression than in

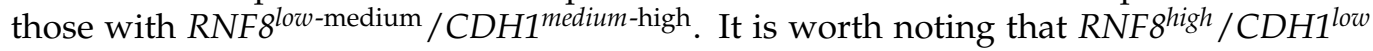




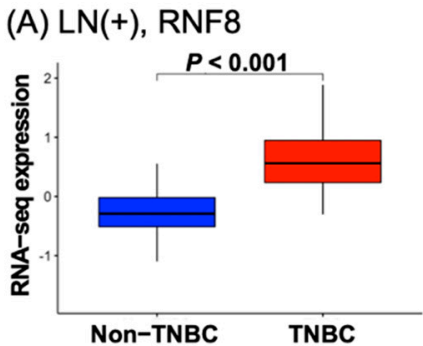

(E) $\mathrm{LN}(+), \mathrm{CDH} 1$

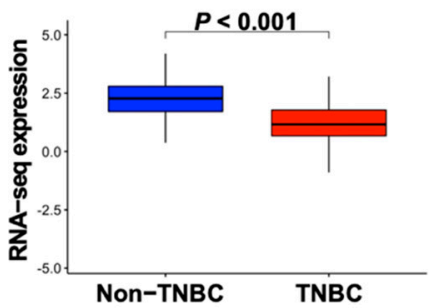

(I) $\mathrm{LN}(+), \mathrm{CDH} 2$

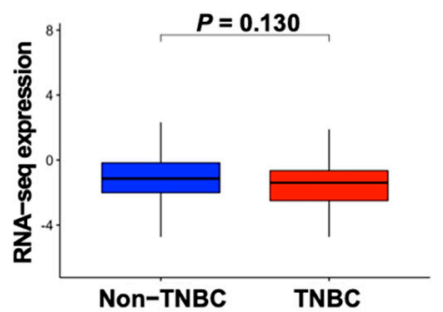

(M) LN(+), NPHS1

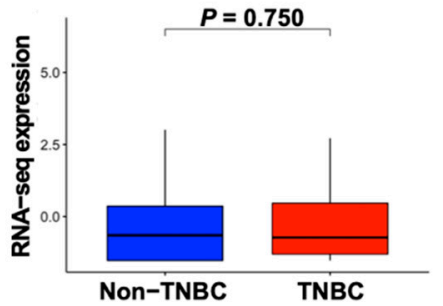

(Q) LN(+), PEBP1

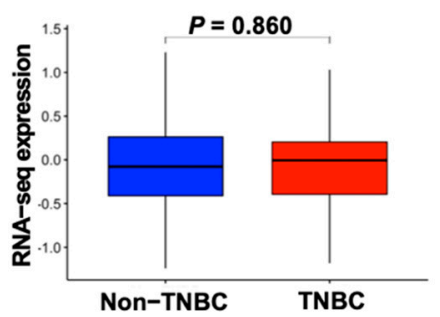

showed a trend of poor DFS when compared to RNF $8^{\text {high }} / C D H 1^{\text {medium-high }}$. These data suggest that the levels of $C D H 1$ function as a determining factor in the RNF8-mediated malignant phenotype in LN+ TNBC (Figure 4E). In contrast, there was no difference between RNF8 $8^{\text {high }} / S N A L 1^{\text {high }}$ and RNF8 $8^{\text {low-medium }} / S N A L 1^{\text {low-medium }}$ in LN+ TNBC patients (Figure 4F). Taken together, these data suggest that the RNF8-CDH1 axis might be an optimal cluster in the impact of baseline clinical characteristics and risk on survival outcome.
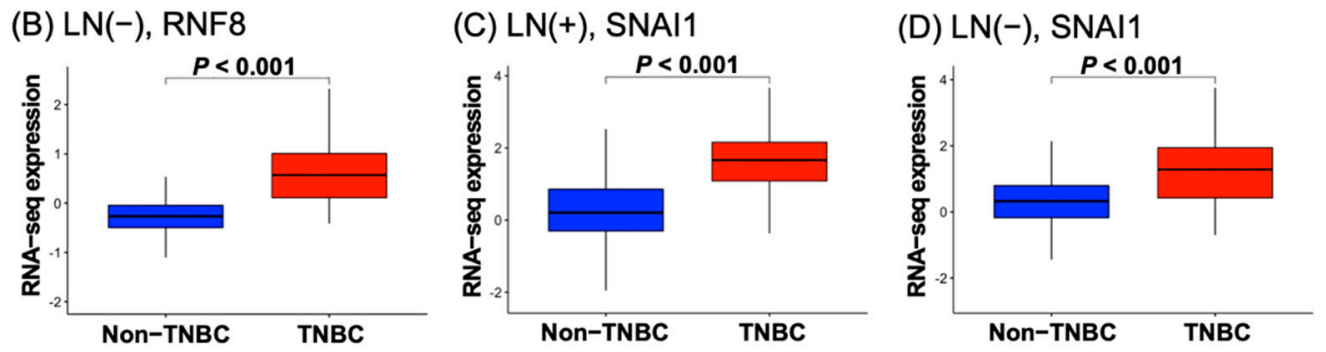

(F) LN(-), CDH1

(G) LN(+), ATK2
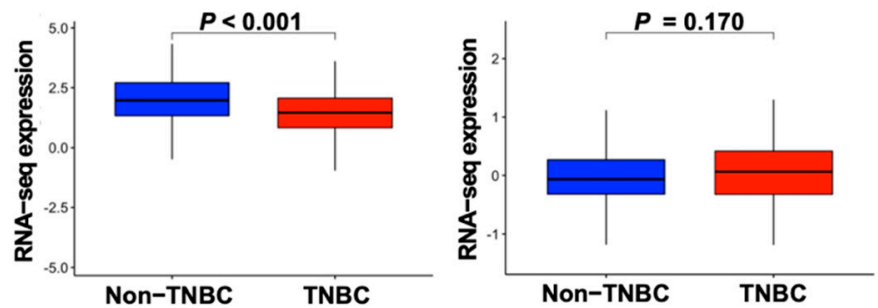

(H) LN(-), ATK2

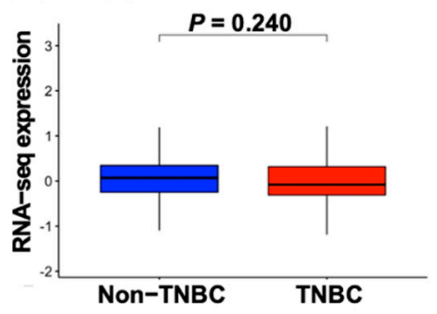

(J) LN(-), $\mathrm{CDH} 2$

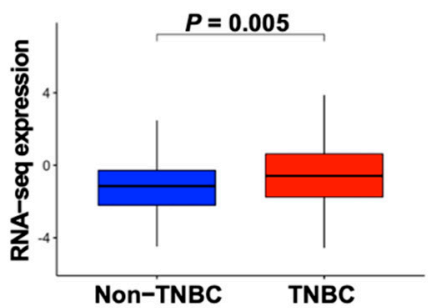

(K) LN(+), CDKN1A

(L) LN(-), CDKN1A
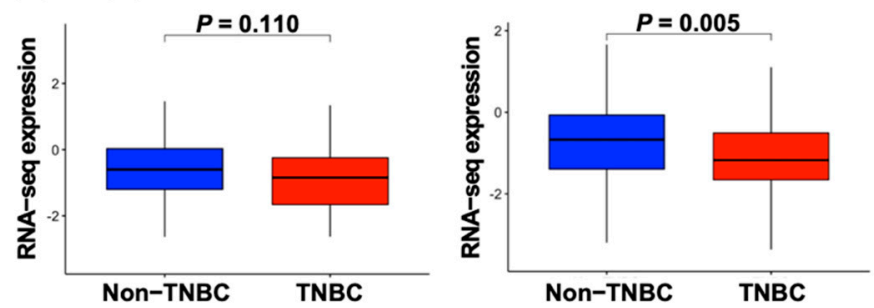

(N) LN(-), NPHS1

(O) LN(+), PDGFRA

(P) LN(-), PDGFRA
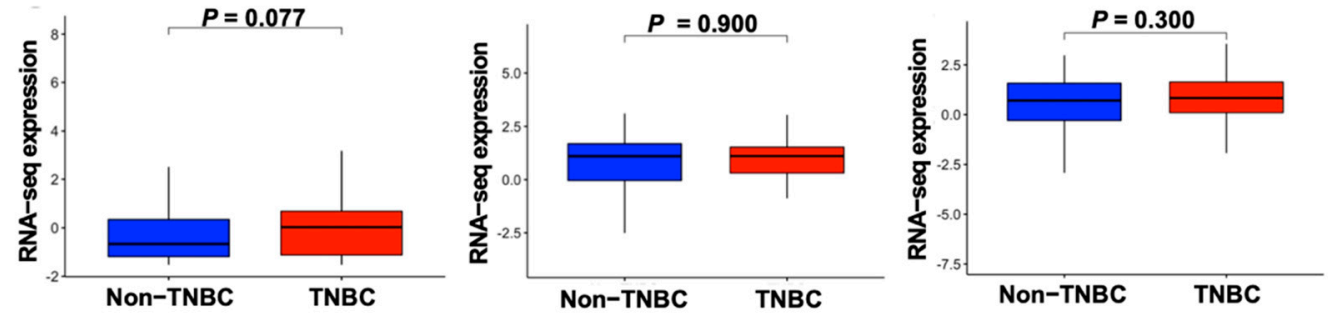

(R) LN(-), PEBP1

(S) LN(+), TGFB2

(T) LN(-), TGFB2
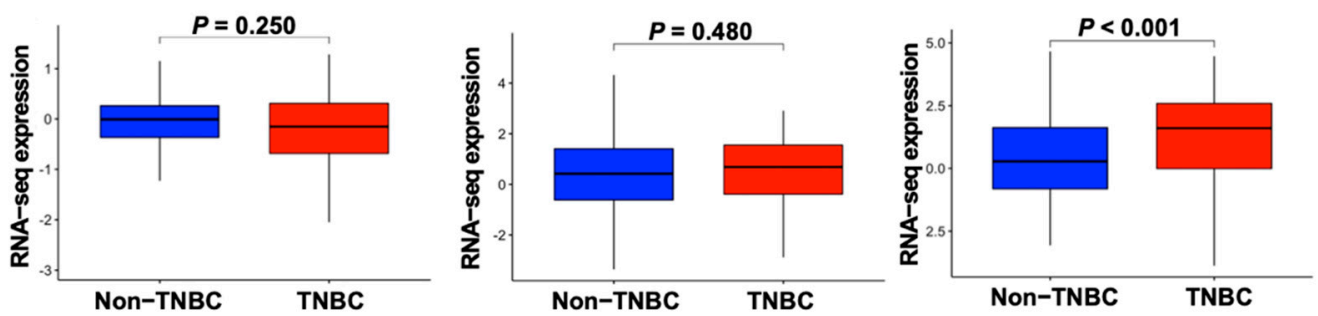

Figure 1. Boxplot of RNA-seq expression in TNBC and non-TNBC according to LN invasion status. (A,B) RNF8, (C,D) SNAI1,

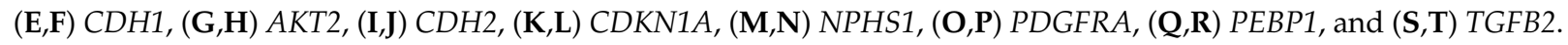


(A)

\section{RNF8}
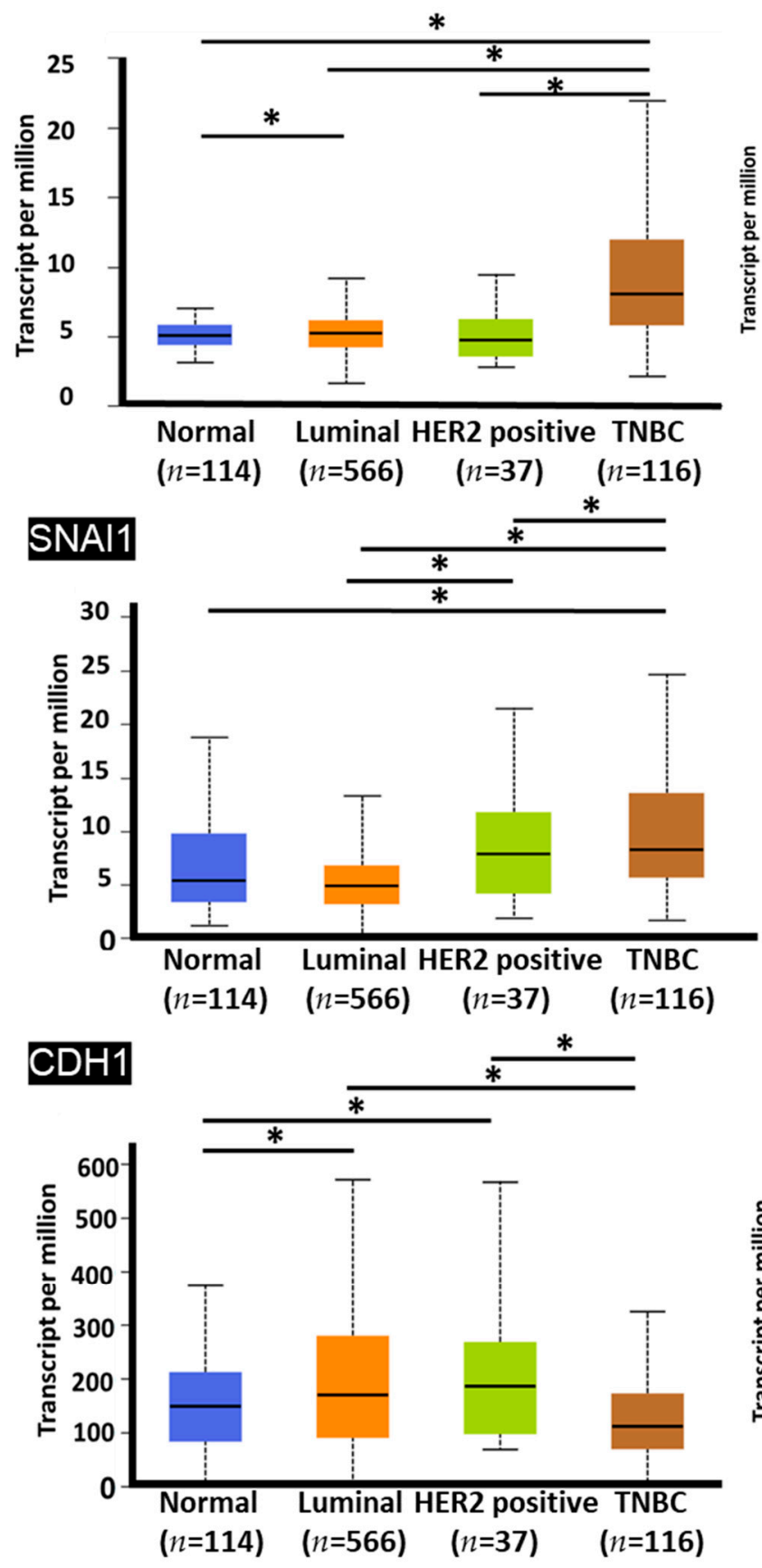

(B)

\section{RNF8}
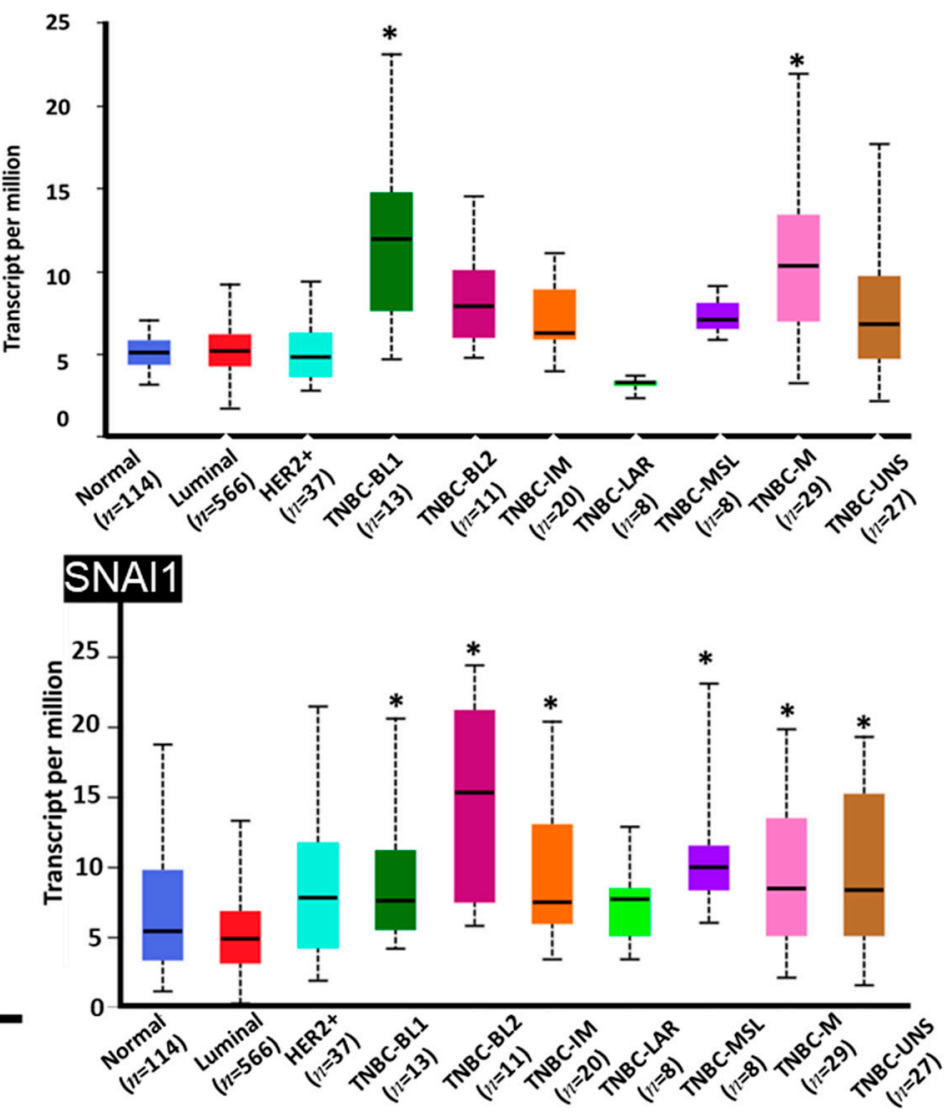

\section{$\mathrm{CDH} 1$}

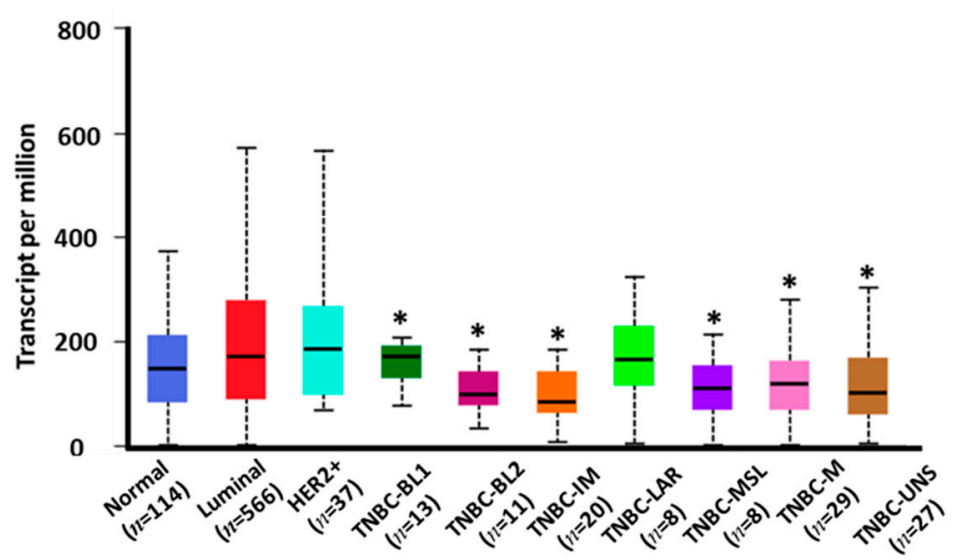

Figure 2. UALCAN portal analysis of breast cancer samples from the TCGA database. (A) Comparison of RNF8, SNAI1, and $C D H 1$ expression levels between normal and different subtypes of breast cancer samples. Normal, $n=114 ;$ luminal, $n=566$; HER2+, $n=37$; TNBC, $n=116$. (B) Expression of RNF8, SNAI1, and CDH1 between different TNBC subgroups. Normal, $n=114$; luminal, $n=566$; HER2+, $n=37$; TNBC-BL1, $n=13$; TNBC-BL2, $n=11$; TNBC-IM, $n=20$; TNBC-LAR, $n=8$; TNBC-MSL, $n=8$; TNBC-M, $n=29$; TNBC-UNS, $n=27 .{ }^{*} p<0.05$. TNBC, triple-negative breast cancer; TCGA, The

Cancer Genome Atlas. 
(A) RNF8

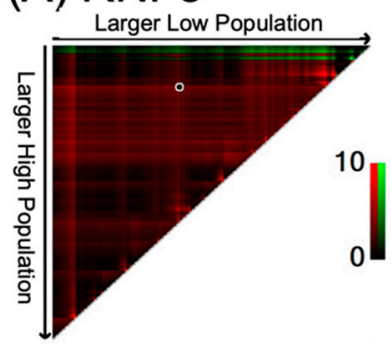

(B) $\mathrm{CDH} 1$

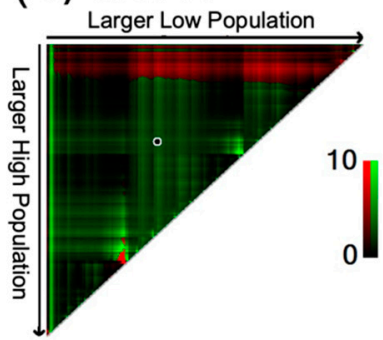

(C) SNAI1

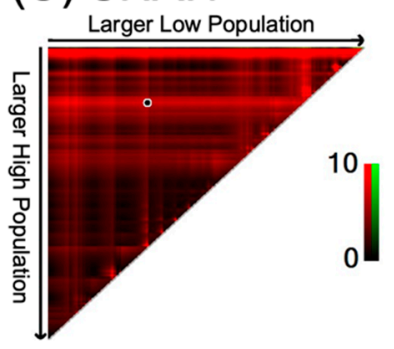

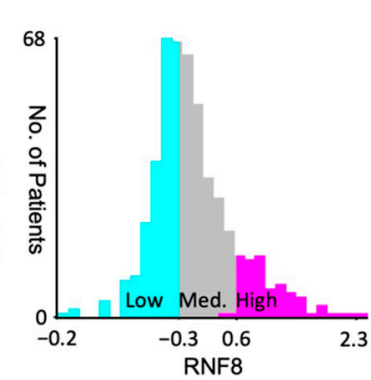
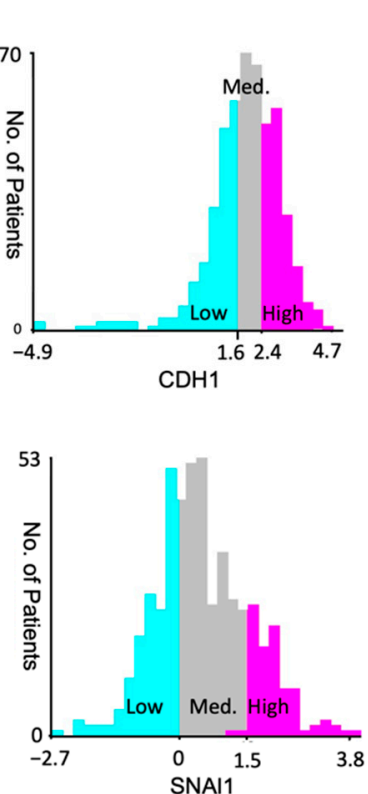

(D) RNF8 × CDH1

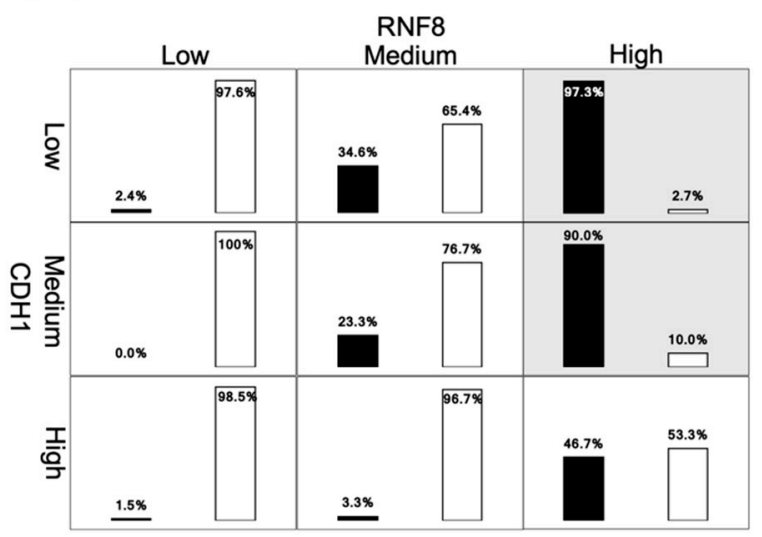

(E) RNF8 × SNAI1

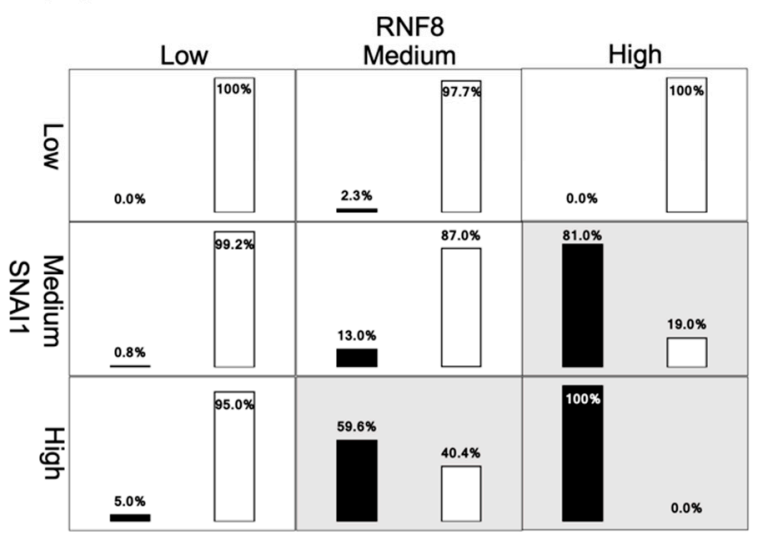

Figure 3. The high, medium, and low subgroups for RNA-seq expression according to DFS using X-tile algorithm. (A) RNF8, (B) CDH1, and (C) SNAI1. The right panel graphically represents a right-triangular grid in which each point indicates the RNA-seq expression in a study population. The x-axis represents all possible "low" samples with the size of the low samples increasing from left to right, and the y-axis represents all possible "high" samples with the size of the high samples increasing from top to bottom. The left panel represents the number of patients in high, medium, and low subgroups stratified by $\mathrm{X}$-tile algorithm. (D) Distribution of TNBC and non-TNBC in each RNF8 $\times$ CDH1 strata among LN- subgroup. (E) Distribution of TNBC and non-TNBC in each RNF8 $\times$ SNAI1 strata among LN+ subgroup. Black bar represents proportion of TNBC; white bar represents proportion of non-TNBC. Stratum marked in gray color indicates higher TNBC proportion compared to non-TNBC. DFS, disease-free survival; TNBC, triple-negative breast cancer.

\subsection{Radiation Combined with Chemotherapy Improves the Survival of Node-Positive RNF sigh $^{\text {CCDH1 }}{ }^{\text {low }}$}

Evidence indicates that adjuvant radiotherapy (RT) reduces the 10-year first risk of recurrence after surgery and systemic therapy in LN+ breast cancers [34]. The NCCN guidelines indicate that patients with more than four positive LN should receive RT. In addition to this rule, identification of biomarkers to provide predictive information regarding a tumor's intrinsic radio-response to treatment could avoid radiation-induced toxicity in patients and establish a personalized therapeutic strategy. RNF8 is a DNA damage response protein that contributes to DNA repair. To verify the role of $R N F 8^{\text {high }} / C D H 1^{\text {low }}$ in response to RT, LN+ TNBC patients were treated with RT or non-RT, and survival outcomes were analyzed according to the expression of $R N F 8^{\text {high }} / C D H 1^{\text {low }}$. As it is shown in Figure 5A, RNF8 ${ }^{\text {high }} / C D H 1^{\text {low }}$ showed a strong trend of poor PFS when compared to

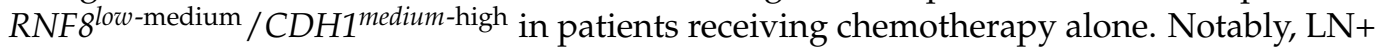
TNBC patients with $R N F 8^{\text {high }} / C D H 1^{\text {low }}$ and $R N F 8^{\text {low-medium }} / C D H 1^{\text {medium-high }}$ all displayed a better response to the combination of RT treatment (Figure $5 \mathrm{~B}$ ). These data demon- 
strate that combined chemotherapy and radiation improves the survival of node-positive $R N F 8^{h i g h} / C D H 1^{\text {low }}$ (Figure $5 \mathrm{C}$ ). In contrast, there was no difference in the survival rate in patients with $R N F 8^{\text {high }} / C D H 1^{\text {medium-high }}$ treated with $\mathrm{CT}$ alone, and with the CT and RT combination (Figure 5D). As it is shown in Figure 3A, only $2.7 \%$ of $R N F 8^{\text {high }} / C D H 1^{\text {low }}$ was observed in non-TNBC patients. Therefore, there is no meaning in the evaluation of the status of $R N F 8^{h i g h} / C D H 1^{l o w}$ in non-TNBC patients regarding the survival rate (Figure $5 \mathrm{E}, \mathrm{F}$ ). In summary, these data indicate that the status of $R N F 8^{\text {high }} / C D H 1^{\text {low }}$ might provide a guideline for determining combined RT therapy after surgery and systemic therapy in LN+ TNBC patients.

\section{(A) TNBC, LN(+), RNF8}

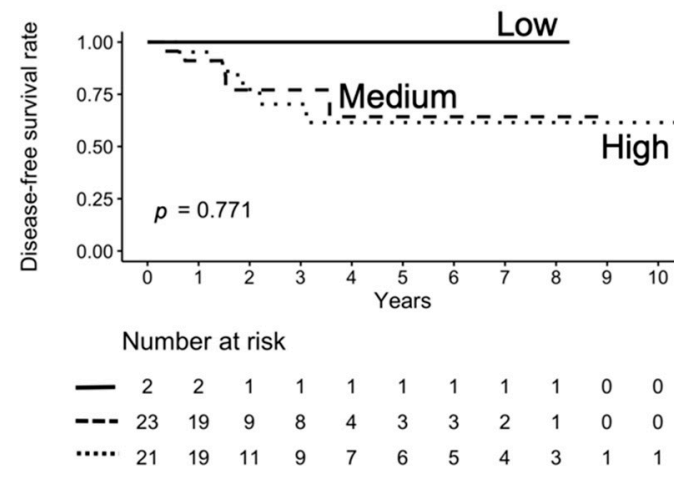

(C) TNBC, LN(+), SNAI1

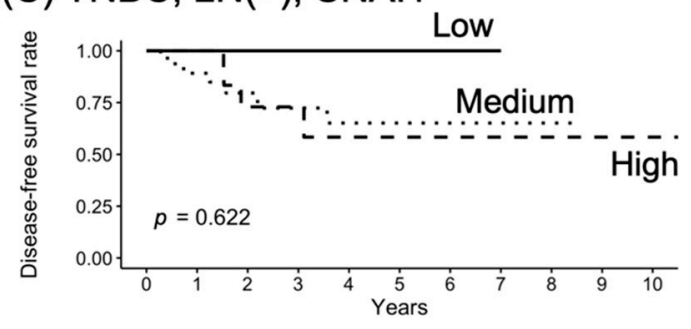

Number at risk

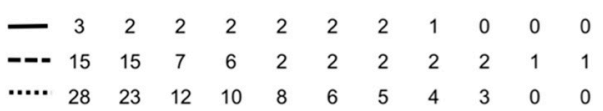

(E) TNBC, LN(+), RNF8 high

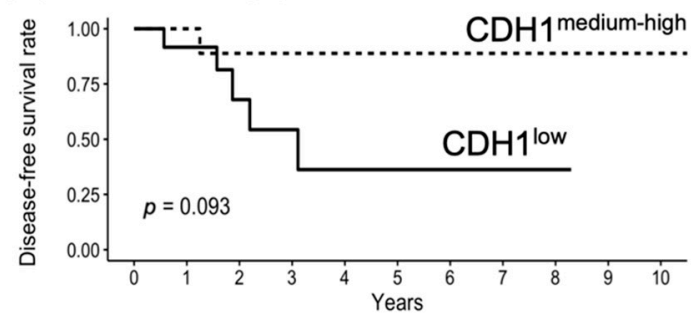

Number at risk

$\begin{array}{llllllllllll}- & 12 & 10 & 5 & 4 & 2 & 2 & 2 & 1 & 1 & 0 & 0\end{array}$
(B) TNBC, LN(+), CDH1

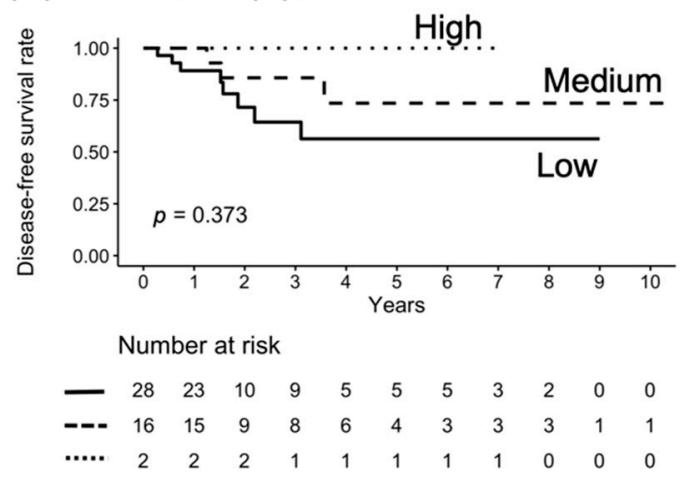

(D) TNBC, LN(+), RNF8-CDH1

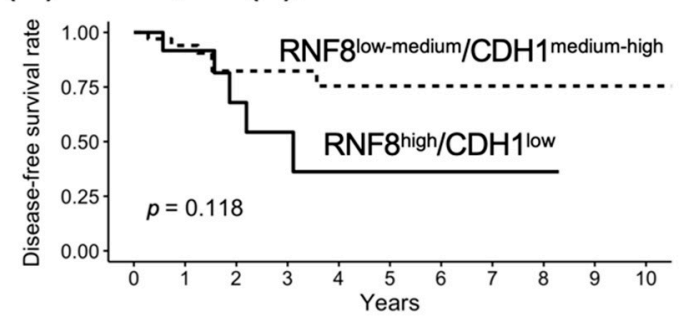

Number at risk

$\begin{array}{llllllllllll}- & 12 & 10 & 5 & 4 & 2 & 2 & 2 & 1 & 1 & 0 & 0\end{array}$

$\begin{array}{llllllllllll}\text {--- } & 34 & 30 & 16 & 14 & 10 & 8 & 7 & 6 & 4 & 1 & 1\end{array}$
(F) TNBC, LN(+), RNF8-SNAI1

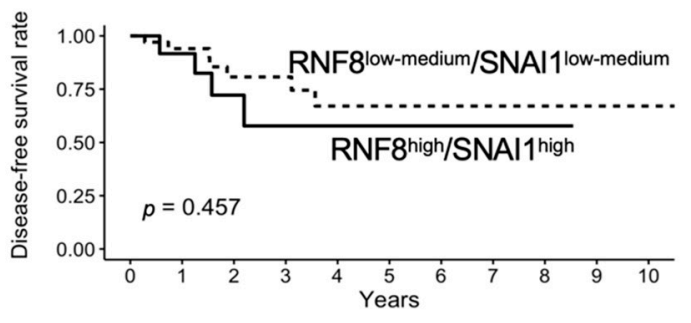

Number at risk

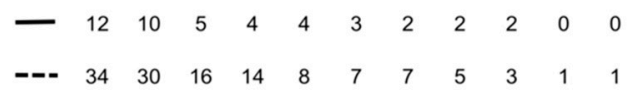

Figure 4. Kaplan-Meier plot for DFS in LN+ TNBC breast cancer according to high-, medium-, and low-RNA-seq expression strata of (A) RNF8, (B) CDH1, (C) SNAI1, (D) RNF8 × CDH1, (E) RNF8 high $/ C D H 1^{\text {low }}$ vs. RNF8 $8^{\text {high }} / C D H 1^{\text {medium-high }}$, and (F) RNF8 $\times$ SNAI1 in LN+ TNBC according to RNA-seq expression. DFS, disease-free survival; LN, lymph nodes; TNBC, triple-negative breast cancer. 


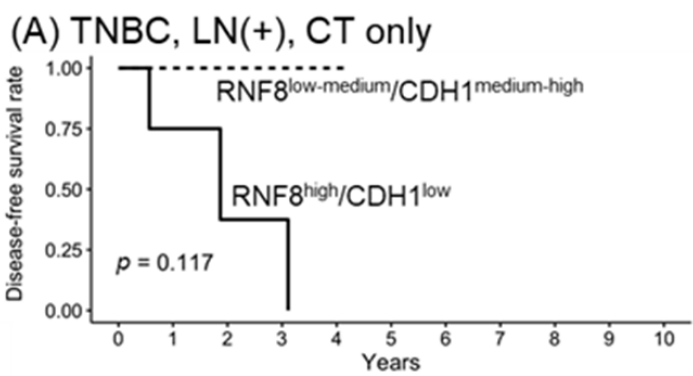

Number at risk

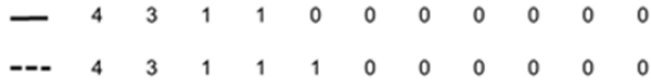

(C) TNBC, LN(+), RNF8 ${ }^{\text {high }} / \mathrm{CDH} 1^{\text {low }}$

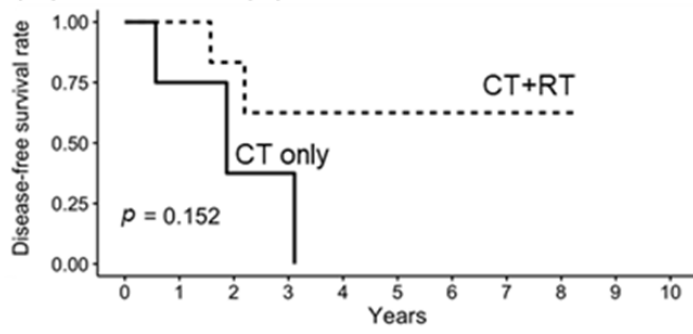

Number at risk

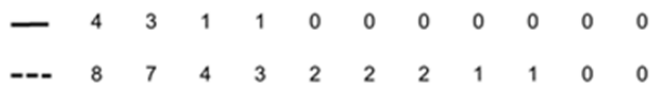

(E) Non-TNBC, LN(+), CT only

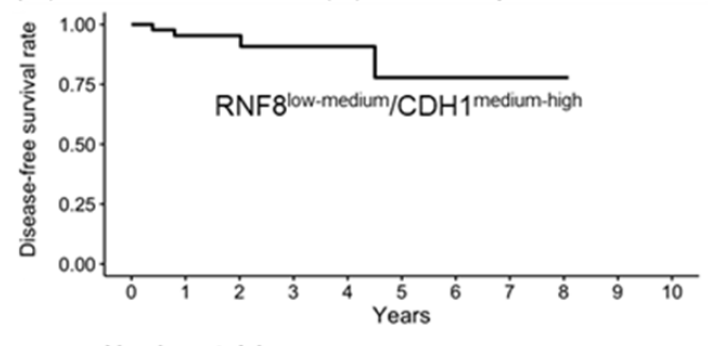

Number at risk

$\begin{array}{llllllllllll}- & 44 & 40 & 21 & 14 & 13 & 4 & 2 & 2 & 1 & 0 & 0\end{array}$
(B) TNBC, LN(+), CT+RT

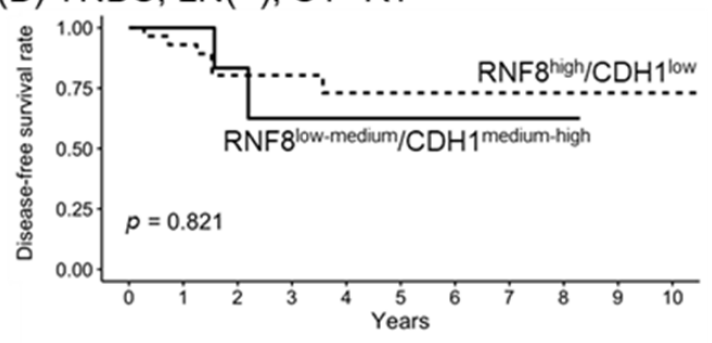

Number at risk

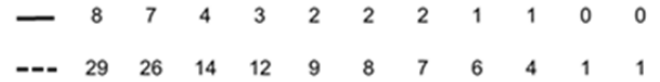

(D) TNBC, LN(+), RNF8 ${ }^{\text {high }} / \mathrm{CDH} 1^{\text {medium-high }}$

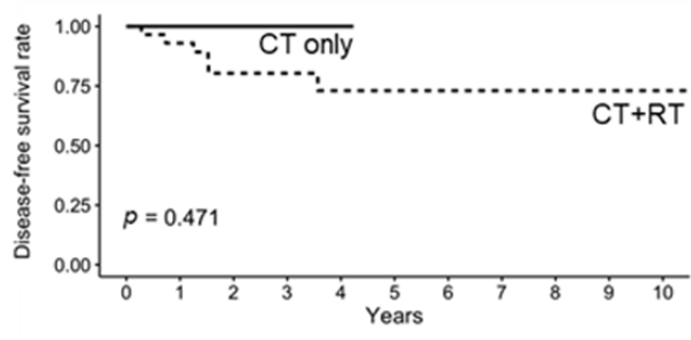

Number at risk

$\begin{array}{llllllllllll}- & 4 & 3 & 1 & 1 & 1 & 0 & 0 & 0 & 0 & 0 & 0\end{array}$

(F) Non-TNBC, LN(+), CT+RT

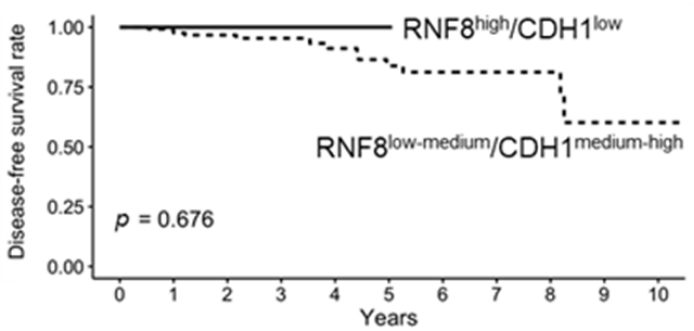

Number at risk

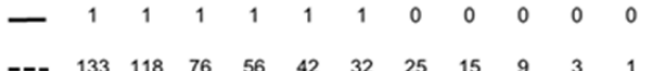

$\begin{array}{llllllllllll}--- & 133 & 118 & 76 & 56 & 42 & 32 & 25 & 15 & 9 & 3 & 1\end{array}$

Figure 5. Kaplan-Meier plot for DFS in LN+ TNBC breast cancer according to high-, medium-, and low-RNA-seq ex-

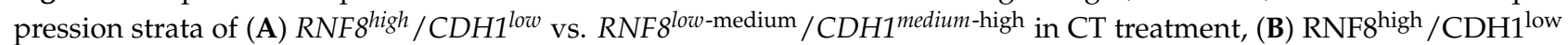
vs. $\mathrm{RNF}^{\text {low-medium }} / \mathrm{CDH} 1^{\text {medium-high }}$ in $\mathrm{CT}+\mathrm{RT}$ treatment, $(\mathrm{C}) \mathrm{RNF} 8^{\text {high }} / \mathrm{CDH} 1^{\text {low }}$ in $\mathrm{CT}$ and $\mathrm{CT}+\mathrm{RT}$ treatment, (D) $R N F 8^{\text {high }} / C D H 1^{\text {medium-high }}$ in $\mathrm{CT}$ and $\mathrm{CT}+\mathrm{RT}$ treatment, (E) $R N F 8^{\text {high }} / C D H 1^{\text {low }}$ vs. RNF8 $8^{\text {low }}$-medium $/ C D H 1^{\text {medium-high }}$ in CT treatment of non-TNBC, and (F) $R N F 8^{\text {high }} / C D H 1^{\text {low }}$ vs. RNF8 $8^{\text {low }}$-medium $/ C D H 1^{\text {medium-high }}$ in $\mathrm{CT}+\mathrm{RT}$ treatment of non-TNBC RNA-seq expression. CT, chemotherapy; DFS, disease-free survival; LN, lymph nodes; RT, radiotherapy; TNBC, triple-negative breast cancer.

\section{Discussion}

Compared to other subtypes of breast cancer, TNBC has a high metastatic ability and a poor prognosis. Therefore, it is crucial to understand the mechanisms of metastasis to improve the therapeutic outcomes of TNBC. Studies have indicated that TNBC cells displayed an enriched CSC population and activated the EMT program [12,13]. TWIST overexpression has been shown to function as an EMT initiator in the development of TNBC [14-17]. These studies unequivocally emphasize the pathological importance of TWIST in TNBC, suggesting that blocking EMT by inhibiting TWIST is a compelling approach to targeting 
TNBC. In this study, we conducted a serial comprehensive analysis including RNA-seq data to address the correlation among RNF8, TWIST-mediated downstream genes, and the survival rate in patients with TNBC receiving either $\mathrm{CT}$ alone or CT with RT treatment. We found that $R N F 8^{\text {high }}$ and $C D H 1^{\text {low }}$ were significantly more common in patients with TNBC than in patients without TNBC. Patients with RNF $8^{\text {high }} / C D H 1^{\text {low }}$ displayed a shorter survival rate than those with $R N F 8^{\text {low }}$-medium $/ C D H 1^{\text {medium-high }}$. Notably, combining RT with CT could effectively improve the survival rate in patients with $R N F 8^{\text {high }} / C D H 1^{\text {low }}$ compared to CT alone. RNF8 $8^{\text {low-medium }} / C D H 1^{\text {medium-high }}$ plays a role as a better diagnostic index and is also associated with a better treatment response in patients treated with CT alone.

RNF8 is a ubiquitin E3 ligase that was initially implicated in DNA damage signaling. In recent years, several studies have indicated that RNF8 promotes EMT via K63-linked ubiquitination and subsequent activation and stabilization of EMT-associated proteins, including TWIST, Slug, and $\beta$-catenin, in driving cancer metastasis $[22,35,36]$. Notably, our data also indicate that an increase in RNF8 and SNAI1 mRNA levels and a decrease in CDH1 mRNA were observed in malignant subtypes of breast cancer, i.e., TNBC patients (Figure 1).

Recently, genetic profiling has been discovered as a strategy to personalized therapy in clinical research on TNBC treatment. For example, PARP inhibitors have been suggested for use in germline $B R C A$ mutation-associated breast cancer (gBRCAm-BC), and checkpoint inhibitor atezolizumab combined with nab-paclitaxel in programmed cell death-ligand 1-positive (PD-L1+) advanced TNBC [37,38]. Although neoadjuvant therapy has focused on combinations of systemic agents to optimize the pathologically complete response, TNBC still has a poor prognosis and clinical outcomes. Generally, tumor heterogeneity is a major concern for poor treatment response in patients with TNBC. Lehman and colleagues first reported further classification of TNBC based on the tumor gene expression profile $[33,39]$. By analyzing microarray data, they identified six molecular subtypes characterized not only by distinct patterns of the gene expression signature but also by very diverse clinical behaviors; basal-like subtypes (BL1 and BL2) constituted approximately $70 \%$ of TN tumors. The BL1 subtype expresses genes involved in cell cycle regulation, cell proliferation, and DNA damage response, whereas BL2 highly expresses genes involved in the cell cycle, cell division, and growth factor signaling. BL1 tumors are almost exclusively of a ductal histology and a high grade and achieve a higher pathological complete response $(\mathrm{pCR})$ rate when treated with neoadjuvant chemotherapy. Explicitly, BL2-subtype tumors are less likely to achieve $\mathrm{pCR}$ and have a higher risk of recurrence compared to BL1. For aggressive tumors such as TNBC, pCR is accepted as a favorable prognostic marker associated with long-term survival benefits [40]. Mesenchymal (M) and mesenchymal stemlike (MSL) subtypes show high expression of genes involved in EMT and growth factor signaling (EGFR, PDGFR, PI3K/mTOR, Src). Tumors in the M category are less sensitive to chemotherapy than BL1 and preferentially metastasize to the lungs. Metaplastic carcinomas are mostly of the M subtype. Notably, our data indicate that RNF8 was significantly expressed in the BL1 and M types of TNBC (Figure 2). These data suggest that focusing on RNF8 may address the detailed mechanism of DNA damage response and cell motility when acquiring the malignant phenotype of TNBC and further identify a personalized strategy for the development of anti-cancer agents.

In TNBC, conventional systemic CT is the mainstay of treatment. RT combined with CT was explored in $\mathrm{LN}+$ patients. In addition, BRCA1/2 germline mutation can be checked, and PARP inhibitors may be used as the first priority to treat the positive group [37]. However, there is an unmet need for a predictive biomarker for establishing a better therapy. In the present study, we identified that the $R N F 8^{\text {high }} / C D H 1^{\text {low }}$ index not only represented a poor diagnostic marker but also indicated a poor treatment response to $\mathrm{CT}$ treatment alone. The combination of $\mathrm{CT}$ and RT could effectively improve the survival rate in patients with an $R N F 8^{h i g h} / C D H 1^{\text {low }}$ index compared to CT treatment alone. The above evidence suggests that RNF8 may be used as a guiding clue for clinical classification, and the precise 
treatment can be further clarified in concurrent chemoradiation (CCRT) selection to avoid over-treatment. It is worth noting that the retrospective nature of current study might limit the inclusion of all relevant prognostic variables (e.g., demographic area, education level). In addition, the multi-factor interaction effect, especially the marginal effects, was not comprehensively considered, and further application of a machine learning algorithm was required to estimate the high-dimensional interaction between gene expression. Despite the mentioned limitations, this study proposes a novel data-driven therapeutic effect estimation approach based on an open access, real-world database, which could offer quick access to identifying potential anti-cancer candidate genes and provide added value for integrated cancer databases.

\section{Conclusions}

In our study, we first focused on different genes and noticed that enrichment in RNF8 may be the most representative, also indicating a relatively poor prognosis, especially in the TNBC group. In addition, we found that the RNF8-CDH1 co-expression could predict the outcome of breast cancer. $R N F 8^{\text {high }} / C D H 1^{\text {low }}$ functions as a poor prognostic marker in LN+ TNBC patients. This suggests different strategies for treatment. As we know, adjuvant radiotherapy may not be indicated for patients with a low level of LN metastasis (or micrometastasis group). However, according to our study, adjuvant radiotherapy to the axillary area may be suggested in patients with $R N F 8^{\text {high }} / C D H 1^{\text {low }}$ due to the high recurrence rate, although the lymph nodal number is lower.

Author Contributions: Conceptualization, M.-R.P.; methodology, S.-H.M.; data curation, S.-H.M. and C.-N.K.; investigation, M.-F.H. and F.-M.C.; supervision, M.-R.P. and M.-F.H.; writing-original draft, C.-N.K., S.-H.M., and C.-W.L.; writing-review and editing, M.-R.P. All authors have read and agreed to the published version of the manuscript.

Funding: (1) KMUH-DK(C)110005, KMUH-DK-109001, KMUH108-8R36, and KMUH109-9R37 from the Kaohsiung Medical University Hospital; (2) MOHW109-TDU-B-212-010001 from the Ministry of Health and Welfare, Taiwan; (3) KMU-DK108011, KMU-DK-109003-1, KMUH-DK-109003-2, and KMUH-DK-109003-3 from KMU-KMUH Co-Project of Key Research; (4) 110-2320-B-037-006-, 1102628-B-037-011-, 110-2321-B-037-002-, 109-2314-B-037-019, 109-2314-B-037-132-, and 109-2314-B-037036-MY3 from the Ministry of Science and Technology, Taiwan; (5) KMU-KI110001, KMU-TC109A03, KMU-TC108A03-6, and KMU-TC109B05 from Kaohsiung Medical University Research Center Grant.

Institutional Review Board Statement: Not applicable.

Informed Consent Statement: Not applicable.

Data Availability Statement: The data presented in this study are available in the article.

Conflicts of Interest: The authors declare no conflict of interest.

\section{References}

1. O'Reilly, E.A.; Gubbins, L.; Sharma, S.; Tully, R.; Guang, M.H.; Weiner-Gorzel, K.; McCaffrey, J.; Harrison, M.; Furlong, F.; Kell, M.; et al. The fate of chemoresistance in triple negative breast cancer (TNBC). BBA Clin. 2015, 3, 257-275. [CrossRef]

2. Son, H.; Moon, A. Epithelial-mesenchymal transition and cell invasion. Toxicol. Res. 2010, 26, 245-252. [CrossRef]

3. National Comprehensive Cancer Network. NCCN Clinical Practice Guidelines in Oncology (NCCN Guidelines): Breast Cancer (Version 5.2021). 2021. Available online: https://www.nccn.org/professionals/physician_gls (accessed on 13 July 2021).

4. Cardoso, F.; Senkus, E.; Costa, A.; Papadopoulos, E.; Aapro, M.; André, F.; Harbeck, N.; Aguilar Lopez, B.; Barrios, C.H.; Bergh, J.; et al. 4th ESO-ESMO international consensus guidelines for advanced breast cancer (ABC 4). Ann. Oncol. 2018, $29,1634-1657$. [CrossRef]

5. Schmid, P.; Adams, S.; Rugo, H.S.; Schneeweiss, A.; Barrios, C.H.; Iwata, H.; Diéras, V.; Hegg, R.; Im, S.A.; Shaw Wright, G.; et al. Atezolizumab and Nab-Paclitaxel in advanced triple-negative breast cancer. N. Engl. J. Med. 2018, 379, 2108-2121. [CrossRef]

6. Kalluri, R.; Weinberg, R.A. The basics of epithelial-mesenchymal transition. J. Clin. Investig. 2009, 119, 1420-1428. [CrossRef]

7. Xu, J.; Lamouille, S.; Derynck, R. TGF-beta-induced epithelial to mesenchymal transition. Cell Res. 2009, 19, 156-172. [CrossRef]

8. Fantozzi, A.; Gruber, D.C.; Pisarsky, L.; Heck, C.; Kunita, A.; Yilmaz, M.; Meyer-Schaller, N.; Cornille, K.; Hopfer, U.; Bentires-Alj, M.; et al. VEGF-mediated angiogenesis links EMT-induced cancer stemness to tumor initiation. Cancer Res. 2014, 74, 1566-1575. [CrossRef] [PubMed] 
9. Sullivan, N.J.; Sasser, A.K.; Axel, A.E.; Vesuna, F.; Raman, V.; Ramirez, N.; Oberyszyn, T.M.; Hall, B.M. Interleukin-6 induces an epithelial-mesenchymal transition phenotype in human breast cancer cells. Oncogene 2009, 28, 2940-2947. [CrossRef] [PubMed]

10. Kim, J.; Kong, J.; Chang, H.; Kim, H.; Kim, A. EGF induces epithelial-mesenchymal transition through phospho-Smad2/3-Snail signaling pathway in breast cancer cells. Oncotarget 2016, 7, 85021-85032. [CrossRef] [PubMed]

11. Gheldof, A.; Berx, G. Cadherins and epithelial-to-mesenchymal transition. Prog Mol. Biol. Transl. Sci. 2013, 116, 317-336. [CrossRef]

12. May, C.D.; Sphyris, N.; Evans, K.W.; Werden, S.J.; Guo, W.; Mani, S.A. Epithelial-mesenchymal transition and cancer stem cells: A dangerously dynamic duo in breast cancer progression. Breast Cancer Res. 2011, 13, 202. [CrossRef]

13. Cazet, A.S.; Hui, M.N.; Elsworth, B.L.; Wu, S.Z.; Roden, D.; Chan, C.L.; Skhinas, J.N.; Collot, R.; Yang, J.; Harvey, K.; et al. Targeting stromal remodeling and cancer stem cell plasticity overcomes chemoresistance in triple negative breast cancer. Nat. Commun. 2018, 9, 2897. [CrossRef] [PubMed]

14. Park, S.Y.; Choi, J.H.; Nam, J.S. Targeting cancer stem cells in triple-negative breast cancer. Cancers 2019, 11, 965. [CrossRef] [PubMed]

15. Kim, C.; Gao, R.; Sei, E.; Brandt, R.; Hartman, J.; Hatschek, T.; Crosetto, N.; Foukakis, T.; Navin, N.E. Chemoresistance evolution in triple-negative breast cancer delineated by single-cell sequencing. Cell 2018, 173, 879-893.e13. [CrossRef]

16. Zhang, D.; Sun, B.; Zhao, X.; Ma, Y.; Ji, R.; Gu, Q.; Dong, X.; Li, J.; Liu, F.; Jia, X.; et al. Twist1 expression induced by sunitinib accelerates tumor cell vasculogenic mimicry by increasing the population of CD133+ cells in triple-negative breast cancer. Mol. Cancer 2014, 13, 207. [CrossRef] [PubMed]

17. Zhu, Q.Q.; Ma, C.; Wang, Q.; Song, Y.; Lv, T. The role of TWIST1 in epithelial-mesenchymal transition and cancers. Tumour Biol. 2016, 37, 185-197. [CrossRef]

18. Vesuna, F.; van Diest, P.; Chen, J.H.; Raman, V. Twist is a transcriptional repressor of E-cadherin gene expression in breast cancer. Biochem. Biophys. Res. Commun. 2008, 367, 235-241. [CrossRef]

19. Thuault, S.; Valcourt, U.; Petersen, M.; Manfioletti, G.; Heldin, C.H.; Moustakas, A. Transforming growth factor-beta employs HMGA2 to elicit epithelial-mesenchymal transition. J. Cell Biol. 2006, 174, 175-183. [CrossRef]

20. Sun, S.; Ning, X.; Zhang, Y.; Lu, Y.; Nie, Y.; Han, S.; Liu, L.; Du, R.; Xia, L.; He, L.; et al. Hypoxia-inducible factor-1alpha induces Twist expression in tubular epithelial cells subjected to hypoxia, leading to epithelial-to-mesenchymal transition. Kidney Int. 2009, 75, 1278-1287. [CrossRef]

21. Cheng, G.Z.; Zhang, W.Z.; Sun, M.; Wang, Q.; Coppola, D.; Mansour, M.; Xu, L.M.; Costanzo, C.; Cheng, J.Q.; Wang, L.H. Twist is transcriptionally induced by activation of STAT3 and mediates STAT3 oncogenic function. J. Biol. Chem. 2008, 283, 14665-14673. [CrossRef]

22. Lee, H.J.; Li, C.F.; Ruan, D.; Powers, S.; Thompson, P.A.; Frohman, M.A.; Chan, C.H. The DNA Damage Transducer RNF8 Facilitates Cancer Chemoresistance and Progression through Twist Activation. Mol. Cell 2016, 63, 1021-1033. [CrossRef]

23. Kolas, N.K.; Chapman, J.R.; Nakada, S.; Ylanko, J.; Chahwan, R.; Sweeney, F.D.; Panier, S.; Mendez, M.; Wildenhain, J.; Thomson, T.M.; et al. Orchestration of the DNA-damage response by the RNF8 ubiquitin ligase. Science 2007, 318, 1637-1640. [CrossRef] [PubMed]

24. Mailand, N.; Bekker-Jensen, S.; Faustrup, H.; Melander, F.; Bartek, J.; Lukas, C.; Lukas, J. RNF8 ubiquitylates histones at DNA double-strand breaks and promotes assembly of repair proteins. Cell 2007, 131, 887-900. [CrossRef] [PubMed]

25. Bartocci, C.; Denchi, E.L. Put a RING on it: Regulation and inhibition of RNF8 and RNF168 RING finger E3 ligases at DNA damage sites. Front. Genet. 2013, 4, 128. [CrossRef]

26. Camp, R.L.; Dolled-Filhart, M.; Rimm, D.L. X-tile: A new bio-informatics tool for biomarker assessment and outcome-based cut-point optimization. Clin. Cancer Res. 2004, 10, 7252-7259. [CrossRef]

27. Cheng, G.Z.; Chan, J.; Wang, Q.; Zhang, W.; Sun, C.D.; Wang, L.H. Twist transcriptionally up-regulates AKT2 in breast cancer cells leading to increased migration, invasion, and resistance to paclitaxel. Cancer Res. 2007, 67, 1979-1987. [CrossRef] [PubMed]

28. Fan, Q.; Qiu, M.T.; Zhu, Z.; Zhou, J.H.; Chen, L.; Zhou, Y.; Gu, W.; Wang, L.H.; Li, Z.N.; Xu, Y.; et al. Twist induces epithelialmesenchymal transition in cervical carcinogenesis by regulating the TGF- $\beta$ /Smad3 signaling pathway. Oncol. Rep. 2015, 34, 1787-1794. [CrossRef]

29. Zhao, Z.; Rahman, M.A.; Chen, Z.G.; Shin, D.M. Multiple biological functions of Twist1 in various cancers. Oncotarget 2017, 8, 20380-20393. [CrossRef]

30. Xu, Y.; Qin, L.; Sun, T.; Wu, H.; He, T.; Yang, Z.; Mo, Q.; Liao, L.; Xu, J. Twist1 promotes breast cancer invasion and metastasis by silencing Foxa1 expression. Oncogene 2017, 36, 1157-1166. [CrossRef]

31. Tang, H.; Massi, D.; Hemmings, B.A.; Mandalà, M.; Hu, Z.; Wicki, A.; Xue, G. AKT-ions with a TWIST between EMT and MET. Oncotarget 2016, 7, 62767-62777. [CrossRef]

32. Ansieau, S.; Morel, A.P.; Hinkal, G.; Bastid, J.; Puisieux, A. TWISTing an embryonic transcription factor into an oncoprotein. Oncogene 2010, 29, 3173-3184. [CrossRef] [PubMed]

33. Wang, D.Y.; Jiang, Z.; Ben-David, Y.; Woodgett, J.R.; Zacksenhaus, E. Molecular stratification within triple-negative breast cancer subtypes. Sci Rep. 2019, 9, 19107. [CrossRef] [PubMed]

34. McGale, P.; Taylor, C.; Correa, C.; Cutter, D.; Duane, F.; Ewertz, M.; Gray, R.; Mannu, G.; Peto, R.; Whelan, T.; et al. Effect of radiotherapy after mastectomy and axillary surgery on 10-year recurrence and 20-year breast cancer mortality: Meta-analysis of individual patient data for 8135 women in 22 randomised trials. Lancet 2014, 383, 2127-2135. [CrossRef] [PubMed]

35. Ren, L.; Zhou, T.; Wang, Y.; Wu, Y.; Xu, H.; Liu, J.; Dong, X.; Yi, F.; Guo, Q.; Wang, Z.; et al. RNF8 induces $\beta$-catenin-mediated c-Myc expression and promotes colon cancer proliferation. Int. J. Biol. Sci. 2020, 16, 2051-2062. [CrossRef] [PubMed] 
36. Kuang, J.; Min, L.; Liu, C.; Chen, S.; Gao, C.; Ma, J.; Wu, X.; Li, W.; Wu, L.; Zhu, L. RNF8 Promotes Epithelial-Mesenchymal transition in lung cancer cells via stabilization of Slug. Mol. Cancer Res. 2020, 18, 1638-1649. [CrossRef]

37. Zimmer, A.S.; Gillard, M.; Lipkowitz, S.; Lee, J.M. Update on PARP Inhibitors in breast cancer. Curr. Treat. Options Oncol. 2018, 19, 21. [CrossRef]

38. Cyprian, F.S.; Akhtar, S.; Gatalica, Z.; Vranic, S. Targeted immunotherapy with a checkpoint inhibitor in combination with chemotherapy: A new clinical paradigm in the treatment of triple-negative breast cancer. Bosn. J. Basic Med. Sci. 2019, 19, 227-233. [CrossRef]

39. Lehmann, B.D.; Bauer, J.A.; Chen, X.; Sanders, M.E.; Chakravarthy, A.B.; Shyr, Y.; Pietenpol, J.A. Identification of human triple-negative breast cancer subtypes and preclinical models for selection of targeted therapies. J. Clin. Investig. 2011, 121, 2750-2767. [CrossRef]

40. Lehmann, B.D.; Jovanović, B.; Chen, X.; Estrada, M.V.; Johnson, K.N.; Shyr, Y.; Moses, H.L.; Sanders, M.E.; Pietenpol, J.A. Refinement of triple-negative breast cancer molecular subtypes: Implications for neoadjuvant chemotherapy selection. PLoS ONE 2016, 11, e0157368. [CrossRef] 